\title{
Work Based Learning Combined with E-Learning for Acquisition of Management Competences
}

\author{
http://dx.doi.org/10.3991/ijac.v6i2.2677 \\ A. Soeiro \\ Universidade do Porto, Porto, Portugal
}

\begin{abstract}
Partners in E-View project developed and piloted a European Virtual Campus aimed at learners in the work place which focused on enhancing their management skills and competences within a European context. The project began with a needs analysis followed by the creation of the Virtual Campus Framework. This framework utilized a customised open source delivery methodology and a workbased learning module based on the needs analysis aimed at training managers in European enterprises. The module with an emphasis on working within Europe was piloted with about one hundred employees in the UK, Poland, Portugal and Ireland involving four employers. Concrete outcomes from E-View included a Virtual Campus Framework for Work-based learning (WBL) with a sample undergraduate module, two rounds of pilot courses and an online handbook with a description of the experiences gained in creating and delivering this course in the Virtual Campus Framework for Work-based Learning. Webinars were delivered and recorded to illustrate the procedures.
\end{abstract}

Index Terms-Virtual campus, work-based learning, management competences, learning model, e-learning

\section{Structure OF WBL MOdEL}

The model of learning proposed was defined based on the reports produced in the surveys done by each partner in the respective country. These surveys were done with companies interested in developing WBL for competences in management, with the analysis of specialized documentation and with conclusions drawn from past experiences of WBL. A summary of these main recommendations from the reports in terms of users and employers, conclusions from the comparative analysis in terms of universities and other providers, a list of management competences and a framework that addresses the strategies for learning virtually in WBL were combined to propose a structure that fits these diverse requirements.

The chosen structure was defined mainly as a function of the partnership research and dialogue among the stakeholders. The reasons were the updated information from partners, the focused case studies and reports on the elaboration of the model and the quality of the documents produced. Another minor contribution was the set of documents, websites and examples obtained by the partners. The term learning model was also adopted instead of pedagogical model since the objective is to provide effective and efficient training and learning in management competences.

The list of management chosen adopted as learning objectives of the learning model was obtained through the consultation of the results of the surveys and of the research done on general management courses for higher education. To have significance at the European dimension the degree of competences adopted was at levels 5 and 6 of the European Qualification Framework. The strategic model hereby proposed is considered as the basis for the development of the pilot courses. The pilot courses will then be tested by the partnership so a fine tuning of a European proposal may be produced for wider utilization. Results indicate a spectrum of respondents - in that perceptions of study and readiness to embrace (or currently use therein) new technologies was variable to the extreme. However, there were some trends in the responses regarding types of technology preferred in the learning context and these motivated the options presented. The collection of the conclusions and orientations is made essentially through referenced transcriptions from the project reports and published documents consulted. The requirements were decided in terms of stakeholders of WBL: Employers/Companies and Users.

\section{REQUIREMENTS ADOPTED IN MODEL}

\section{A. Employers/Companies}

The main requirements listed were motivated by the relevance in the context also the users and of the providers. These are:

a) Involvement of Employer - This issue addresses the ways to seek employer collaboration in WBL and what form this involvement may take. In fact the employer is an important stakeholder. It is important to have the employer involved either in a formal or informal mode.

b) Type of involvement - Small and large companies have different ways of getting involved in WBL. Large companies may have funds and special programs. Small businesses may need to work in cooperation so costs may be shared by the group.

c) Scope - Large companies may be interested in learning outcomes that have transnational objectives while small businesses may need to respond to local needs in terms of the WBL. It is important to address the issue of the needs of the targeted people.

d) Learning Outcomes - From the surveys there are two types of learning outcomes in WBL. Courses with defined competencies that can be used when the employee needs and courses created to respond to demands from business units for specific training.

e) Content - There are courses in WBL that are associated with management competencies and soft skills. Other types of courses address contexts with a degree of 


\section{SHORT PAPER}

\section{WORK BASED LEARNING COMBINED WITH E-LEARNING FOR ACQUISITION OF MANAGEMENT COMPETENCES}

change in the workplace like specific technical skills training, new product training or new functions.

f) Needs analysis - Some organisations had a diagnostic process implemented to define training needs before commissioning content development or course provision. Other organisations guaranteed to the employee the possibility of defining their own continuing professional development path.

g) Investment - This is an issue that concerns employers since the costs are high in terms of time andprices of the WBL. The return on investment is not easily measured and quantified. Therefore the decision to engage on WBL is most of the times conditioned by the apparent waste of resources.

h) Flexibility - There is also a need for WBL models to be flexible enough to fit into the needs of the workplace schedule and of the employee. The working environment is not always adaptable to learning due to lack of time and to the scarcity of incentives to be trained in the workplace. Mode of delivery is an essential characteristic of a successful WBL.

i) Assessment - Some organizations impose verification of the competencies acquired in WBL. Other

organizations trust the efficiency of the training based on the characteristics of the provider, quality of program and performance of employee. Several types of assessment modalities can be used especially the techniques used in accreditation of prior learning (informal or formal).

j) Social component - Some organisations recommended for a virtual campus of WBL a certain degree

of social architecture and related functionality. This aspect is related with the functionalities that could foster interaction between learners and provide responses to the cultural requests of the companies.

\section{B. Users}

In terms of users the requirements classified as significant for the model proposal were the following:

a) Learning technologies - Users request that technologies used should the creation of the virtual campus on WBL. The model adopted should be effective, friendly and reliable for learners, employers and supporting staff. Especially for learners the environment should promote the desire to participate in the community of practice.

b) Prerequisites - Learners should be undergraduates that have a bachelor degree or a higher education certificate of some kind. It is recommended to have some years of experience although it is not a prerequisite. It is imperative that learners have the intention to improve their personal development.

c) Information for learners - From the beginning the learners should be informed about the minimum technical requirements and protocols necessary to attend the courses. Adequate information about technical and academic support should be provided at the beginning of each course.

d) Learning support - There should be should be learning support available for learners that could respond to specific academic questions about the courses. In addition there should be technical support to respond to issues related with the course daily operation. e) Relevance - Most learners emphasized the importance of the significance of the courses to the work related activities. It is important that the WBL would contribute to an improvement of the possibilities of career progression.

f) Qualification - Some users mentioned the importance of the WBL to contribute to a qualification either academic or professional. It is important to promote the personal development and competences but it is also relevant the contribution to a qualification.

g) Evaluation - It is important to have an assessment of the competences that each worker has or will acquire with WBL. It is significant to reassure each user of the competences they have and of what they are capable of doing.

h) Mobility - The general management competences have a specific attraction since these skills, knowledge and attitudes maybe be used in other workplaces. Therefore the transferability of these competences is a major interest for these WBL courses. It is considered an added value for the mobility of the learners.

i) Fit for purpose - It is important to have a good alignment between the course content and the work context. There should be flexibility to enable learners to bring in work based training needs into the courses. This requires adaptable courses so they can be aligned with work profiles.

j) Access - The courses should be always accessible enabling a permanent use for the learner needs. The learners should be able to have the courses on the subject required instantly once the decision to attend is taken. That requires also an online support especially for the technical questions.

k) Recording - The questions and issues discussed during the administration of the courses should be recorded. The records should include chats, interactions tutor-learner, FAQs and forums. Webinars may also be an adequate record for effective learning.

1) Personal development plan - Courses proposed should be able to respond to personal development plans in a variety of occupations. Courses and respective competences should be defined to encompass a wide range of occupations and professions.

m) Employers involvement - Users mentioned that it is important do include employers in defining the competencies to be delivered and the assessment processes. The assessment could include input from employers, managers or other people in the workplace that can identify changes in behavior and in acquired competencies about the performance in the workplace.

\section{VIRTUAL MODEL PROPOSAL}

\section{A. Providers}

The model adopted has some conditions to be satisfied by the providers that are Higher Education (HE) institutions. The conditions to be implemented by the HE organizations are:

a) Sources - It is generally considered that the primary source of providers is the sector of higher education (HE) institutions for courses on management. However the type of learning (WBL), the set of competences addressed and the form of training brings opportunities for private organizations. There are several examples of virtual 
campus for management that can be used on WBL environments.

b) Example of HE collaboration - One example that shows the collaboration among institutions to address the diversity of the sector is the UK's Learning Through Work online framework. A government funded and driven initiative it planned to act as a hub for UK universities offering WBL resources for learning. It still provides on-line learning services for learning up to $\mathrm{HE}$ level.

c) Vocational - Most of examples of courses available are included in a strategy of professional development, lifelong learning or continuing education. These are courses that are not for academic purposes although credits may be awarded towards a degree or academic certificate.

d) Accreditation - This seems a major function of HE institutions concerning the one of the benefits of these courses. In fact HE can perform the role of the assessor and award credits to the competences acquired through courses of the virtual campus for WBL. HE can also validate the competences for the employers' reassurance of the return on investment. For the users HE can award the credits corresponding to the skills attained.

e) European Qualification Framework (EQF) - The question of using the courses to satisfy the requirements and recognition of qualifications (academic or professional) for different levels is addressed by the EQF. For the purpose of this project the learning outcomes chosen were considered for levels 5 and 6 of the EQF. That assures the transferability of the modules across Europe.

f) Credits - Credits obtained by the courses are relevant especially in the context where there is accountancy of competences acquired. The issue of credits is addressed by the European Credit Transfer System (ECTS) and by the European Credit system for Vocational Education and Training (ECVET). ECTS is more general and is based on work hours. ECVET is based on relative importance of the learning outcomes. Since ECTS is easier to quantify and has been in place for a longer period most HE use it as reference.

g) Complimentary - HE institutions will complement the WBL practice needs providing training for the competences required in each case. That requires a diagnosis and survey of typical situations since it will be impossible to provide individualized training. The repository of courses must be as short as possible to enable being used as pieces of the puzzle created by the learner competences and by the workplace needs gap.

h) Modes - Courses may be a based on strict virtual campus using self-sustained modules. Other options include using face to face sessions or video interactive sessions. These last options may take advantage of the specialization within certain HE institutions of the existing capacities for specific subjects for certain contexts of wok.

i) Responsiveness - HE institutions should be able to tailor programmes to the employer and learner needs. If possible the content of the courses should be presented in as many modes as possible (audio, text, video, image, etc.). Content of courses should be available, easily accessible and displayable in all contexts

\section{B. Framework}

Taking into consideration the conclusions and options the proposed structure and operational mode are defined by:

a) Management competences - The competences listed above need to be refined and adjusted to the levels of the EQF 5 and 6. This list is just a possible set of the learning outcomes for the courses without classification between levels and distribution between knowledge, skills and attitudes. The learning outcomes of each of the WBL courses should be described in accordance with EQF requirements.

b) Modularity - There is a concrete need to have the ability to tailor programmes to the specific needs of particular employers and employees. That can only be done by a modularisation of the courses. Each module is as short as possible with a proper set of learning outcomes. The modules have to be compatible with each other so it is possible to combine any part of the modules.

c) VC Tools - Tools of the virtual campus have to be as simple as possible so the production, utilization and maintenance can be as simple as possible. If possible the $\mathrm{VC}$ tools have to be used to create environments that try to emulate the face to face training. It is recommended to use as many web 2.0 tools as possible to facilitate social interaction.

d) Access - The accessibility of learning materials in the workplace has to be safeguarded so the learner can have the training in real time. This should be accomplished using as many digital tools and documents as possible based on high bandwidth communications. The costs per course should not condition the number of accesses allowing a proper use of the materials as a function of the employee learning style and schedule.

e) Mode - The preferred mode for the VC for WBL is a blended approach with some face to face sessions complemented by the access to digital documents. Since it may not be possible to have face to face sessions it is recommended to use audio or videoconferencing for synchronous communications and use webinars in the other cases. Web 2.0 tools should also be used to alleviate the effect of the virtual training.

f) Content - The content of the learning should be appropriate to the context of the workplace. An agreement should be established by the interested parties to define the learning outcomes of the training. The content, based on learning outcomes, should be done between learners and providers or between employer, employee and provider.

g) Production - Modules can be produced from different HE institutions in accordance with a global plan. Each module should be produced in accordance to the common set of rules agreed by the partnership. Modules may have a different format but have to be compatible. The distribution of learning outcomes among the partners should be in accordance with the capacities and resources.

h) Recognition and accreditation - The VC structure should facilitate, integrate, generate and accommodate the recognition of the competences acquired with the workplace profile. In fact the VC will have success if the training offered is recognized by the provider or by the employer or by both. That can be done using the techniques adopted for recognition of prior learning. 


\section{SHORT PAPER}

\section{WORK BASED LEARNING COMBINED WITH E-LEARNING FOR ACQUISITION OF MANAGEMENT COMPETENCES}

i) Qualification - The structure of the VC should have, whenever possible, the information about the possible use of the competences acquired towards a possible academic or professional accreditation. That can be assured using a previous agreement with a HE institution or with a professional organization.

\section{CONCLUSIONS}

This set of properties defined the frame that conditioned the pilot courses that were tested during the second part of the project E-VIEW. The partnership produced courses that were administered with companies and with their employees to evaluate the advantages and properties of this WBL virtual model. It was expected to obtain recommendations to improve the set of conclusions and that allowed the adaptation to real training environments. The partners managed locally their modules with a connection and articulation using a platform hosted by the coordinator. That allowed the integration and harmonization of the virtual campus.

The results of the second set of courses provided material and outputs that originated a series of webinars that were administered in the final part of the project. These are available at the project website (http://www.eview-project.eu/) and are public. All relevant deliverables of the project are presented for consultation, debate and further development and use by interested stakeholders. The project outputs were evaluated by a rather deep survey of the participants' opinions and critics. The main conclusions from this experience are: that it is necessary for an effective virtual campus to have a learning contract with the learners, the employers and the providers; that it is necessary to take into account the competences that learners are willing to acquire; and that cultural diversity has to be taken into account when designing these types of learning environments.

\section{REFERENCES}

[1] Realin, J., A Model for Work-Based Learning, Organizational Science, Vol. 8, n.6, 1997.

[2] Bradley, C. and Oliver M., Developing e-learning courses for work based learning, (Consulted 23 August 2012), http://www2002.org/CDROM/alternate/703/, 2002.

[3] Lee, G., E-learning Practice: A Framework for the Implementation of Online Learning, ANZMAC, 2009.

[4] "Internal Reports E-VIEW: User needs and Comparative Analysis", University of East London, University of Lodz, NCI Ireland and University of Porto, 2011.

[5] Fink, F. et al, "Understanding Work-Based Learning", IACEE $10^{\text {th }}$ WCCEE, Vienna, Austria, 2006.

[6] Lee, G., From E-reading to E-learning: A Pedagogical Framework for Online Learning, ANZMAC, 2009.

[7] Soeiro, A., "A Case Study of Work Based Learning Using Elearning", FEANI News, Brussels, Belgium, 2010.

\section{AUTHOR}

A. Soeiro is with the Universidade do Porto, DECFEUP, R. Dr. Roberto Frias s/n, 4200-465 Porto, Portugal (e-mail: avsoeiro@fe.up.pt).

This work was supported in part by the European Commission Lifelong Learning Program under project 510483-LLP-1-2010-1-UK-ERASMUSEVC. Manuscript received 15 April 2012. Published as re-submitted by the author 23 July 2013. 